\title{
Tuberculum Meningioma: Orbitopterional Approach
}

\author{
Alexander Yang ${ }^{1} \quad$ Mohammed Aref $^{1} \quad$ A. Samy Youssef ${ }^{1}$ \\ ${ }^{1}$ Department of Neurosurgery, University of Colorado, Aurora, \\ Colorado, United States \\ J Neurol Surg B 2018;79(suppl S2):S219-S220.

\begin{abstract}
Address for correspondence Samy Youssef, MD, PhD, Department of Neurosurgery, University of Colorado, Mail Stop C307, 12631 East 17th Avenue, Aurora, CO 80045, United States
\end{abstract} \\ (e-mail: Samy.Youssef@UCDenver.edu).
}

\begin{abstract}
This is a case of an extensive tuberculum sella meningioma involving the circle of Willis down to the basilar artery that presented with bilateral visual loss worse on the right than left side. A one-piece right orbitopterional approach along the worse eye was used to gain access to the three cranial fossae. The orbitotomy facilitates access to the midline structures and contralateral base of the tumor with minimal brain retraction.

Keywords

- orbitopterional

- meningioma

- vision

- preservation

- tuberculum sella

- tuberculum

- sella
\end{abstract}

\section{Conflict of Interest}

None.

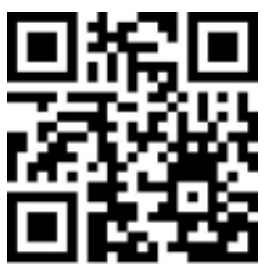

received

October 20, 2017

accepted after revision

November 29, 2017

published online

January 16, 2018

www.thieme.com/skullbasevideos

www.thieme.com/jnlsbvideos

DOI https://doi.org/

10.1055/s-0037-1618599.

ISSN 2193-6331.
๑) 2018 Georg Thieme Verlag KG
Stuttgart · New York

License terms

(c) (i) $\ominus$ (\$) 


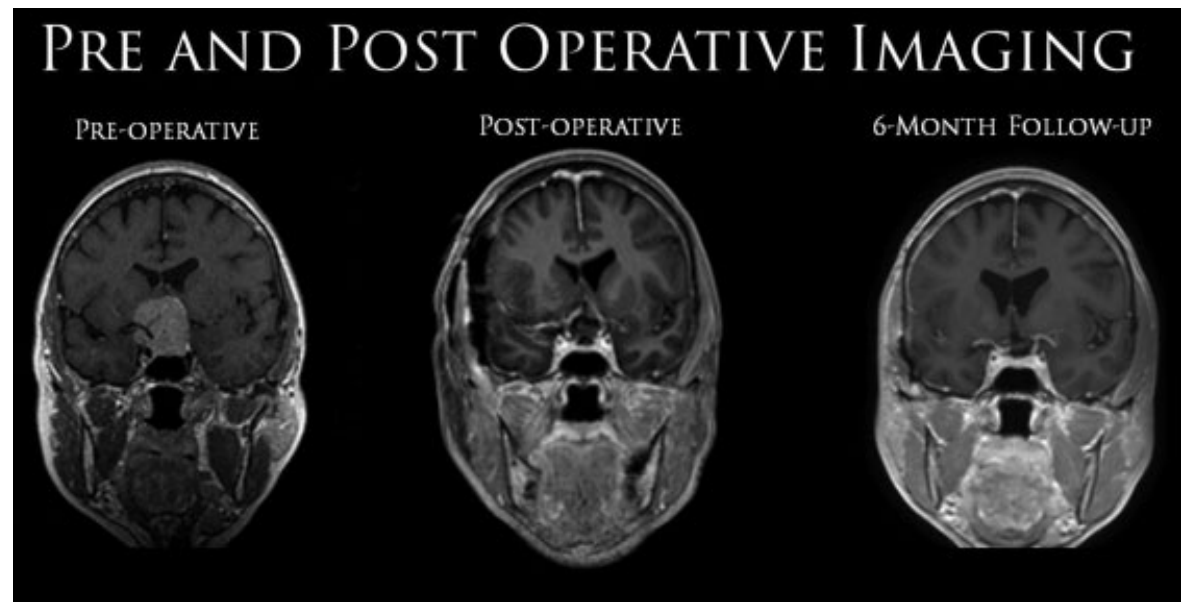

Fig. 1 Preoperative, postoperative, and 6-month follow-up imaging.

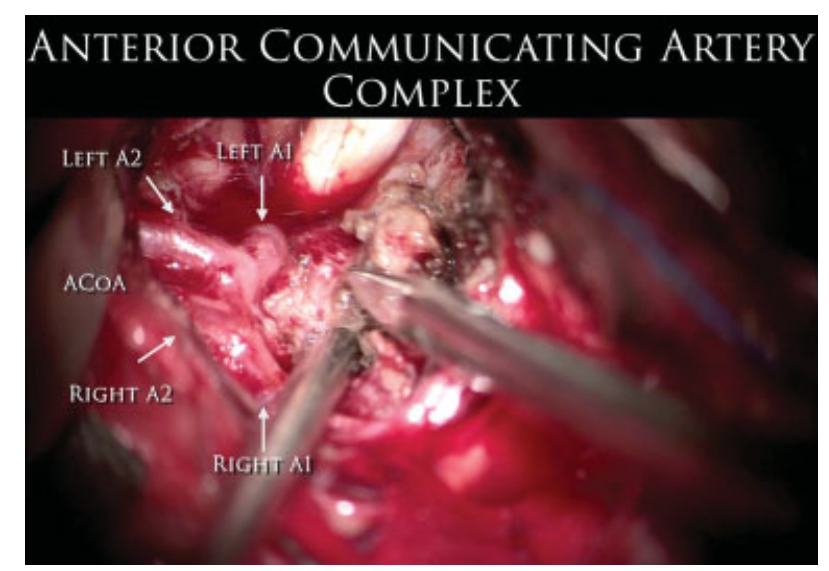

Fig. 2 Anterior communicating artery (ACoA) complex demonstrating vascular segments of the Left A1, Left A2, Right A1, and Right A2 vessels, as well as perforating vessels. 